\title{
Measurements of muscle strength and performance in children with normal and diseased muscle
}

\author{
G. P. HOSKING, U. S. BHAT, V. DUBOWITZ, and R. H. T. EDWARDS \\ From the Departments of Paediatrics and Neonatal Medicine, and the Jerry Lewis Muscle Research Centre, \\ Hammersmith Hospital, London
}

\begin{abstract}
Hosking, G. P., Bhat, U. S., Dubowitz, V., and Edwards, R. H. T. (1976). Archives of Disease in Childhood, 51, 957 . Measurements of muscle strength and performance in children with normal and diseased muscle. A study has been made of two simple means of measuring muscle power in children with normal and diseased muscle. In one the length of time that the leg and the head could be held at $45^{\circ}$ above the horizontal was measured with the child supine. In the second, measurements were made of the isometric strength of six muscle groups with the newly developed Hammersmith Myometer. In the timed performance tests only $5(8 \%)$ of a group of 61 children known to have muscle disease achieved the minimum expected values for their ages. Myometer readings of the isometric power of the children with muscle disease also gave values which were below those of a comparable group of normal children. The reproducibility of muscle strength measurements in young children has been shown to be good, whereas the timed performance tests, though able to differentiate normal children from children with muscle disease, did not show sufficient reproducibility for this test to be recommended for sequential measurements.
\end{abstract}

Weak muscles can be graded according to their ability to act against gravity and a resistance offered by an examiner (Kendall and Kendall, 1938) The Medical Research Council Scale (Medical Research Council, 1943) is a well-known grading systein (see Table I). A disadvantage of such a

\section{TABLE I}

$M R C$ scale for evaluation of muscle power

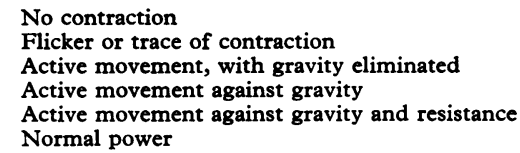

system is the examiner's subjective impression of the resistance being offered by the patient's muscle group (Kendall and Kendall, 1938; Clarke, 1948). This will inevitably give rise to some variation in gradings between different examiners. Furthermore, about $40 \%$ of extremity muscles such as

Received 15 March 1976 rotators and muscles moving the fingers and toes are not significantly affected by the presence or absence of gravity (Wakim et al., 1950; Kendall, Kendall, and Wadsworth, 1971). Lovett, who was the first to suggest the grading of muscle weakness for clinical practice, felt that estimation of muscle power was inexact and should be complemented or replaced by measurement (Lovett, 1915, 1916; Martin and Lovett, 1915; Lovett and Martin, 1916a, b). He devised a test in which the subject maintained a contraction while an attempt was made by the examiner to overcome it by pulling along the line of the muscle with a spring balance which recorded the maximum force achieved.

Lahey (1926) observed that patients with thyrotoxicosis and consequent quadriceps weakness sitting on the edge of a couch were unable to hold their legs horizontal for as long as normal persons. He suggested that this simple test might be of value for identifying a weakness and for following recovery during treatment. Fessel, Taylor, and Johnson (1970) extended this simple form of testing by timing how long a supine patient could hold the leg straight at $45^{\circ}$ above the horizontal, how long the head could be held up at the same angle, and how 
long it took for a patient to rise from the sitting position with the arms folded. These tests were applied to a large number of normal adult subjects and a number of patients with neuromuscular disease, the majority of the latter having significantly lower times.

The Hammersmith Myometer (Fig. 1) was

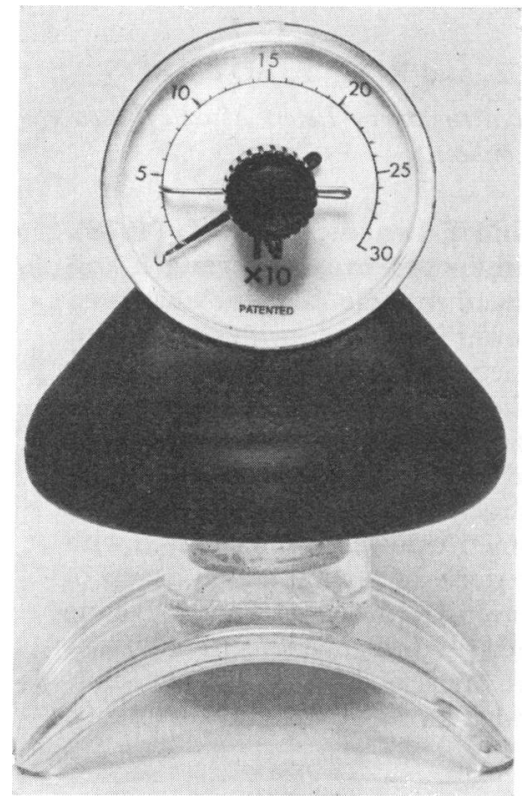

FIG. 1.-Hammersmith Myometer. ${ }^{\star}$

designed as a simple hand-held measuring device that could be used during the course of a normal,

$\star$ Inquiries about purchase of the Myometer to Vickers (Medical) Ltd., Priestly Road, Basingstoke, Hampshire RG24 9NP. clinical examination of the neuromuscular system (Edwards and McDonnell, 1974). It consists of an oil-filled metal bellows and a pressure gauge. By filling the bellows with an incompressible liquid the deformation necessary to register pressure is very small so that the inherent resilience of the bellows need not be taken into account. The myometer had a linear range of 0-220 Newtons (0-22 kgf) with a calibrated accuracy of $\pm 3 \%$.

We have evaluated two means of quantitation of muscle weakness in children with neuromuscular disease as a means of studying the course of a disease and the effects of any therapy which might be offered. Tests similar to those described by Fessel et al. (1970) were applied to a group of normal schoolchildren and to a group of children with neuromuscular disease. The Hammersmith Myometer was used to measure six muscle groups in these children.

\section{Methods}

Normal children. Two surveys of schoolchildren were made. In the first, 300 boys and girls between the ages of 5 and 15 years from three London schools performed two of the tests described by Fessel et al. (1970). Data recorded from each child included height without shoes, weight in indoor clothes, head circumference, chest circumference, age, and sex. Examinations were performed with the children supine. The length of time a leg could be held straight at $45^{\circ}$ and the head at $45^{\circ}$ above the horizontal were recorded. The leg on the stated dominant side was examined. The myometer was used in this survey to measure the strength of the neck flexors and the hip flexors in order to identify faults in design and usage.

In a second survey 215 children between the ages of 5 and 14 years from the same three London schools underwent a study of muscle power using the Hammersmith Myometer. Six muscle groups were examined

TABLE II

Method of myometer examination

\begin{tabular}{|c|c|c|c|}
\hline Muscle group & Position of patient & $\begin{array}{l}\text { Position of part to be } \\
\text { examined }\end{array}$ & Position of myometer \\
\hline Neck flexors & Supine & $\begin{array}{l}\text { Head up at } 45^{\circ} \text { from } \\
\text { horizontal }\end{array}$ & $\begin{array}{l}\text { Centre of forehead } \\
\text { immediately above nose }\end{array}$ \\
\hline Shoulder abductors & Sitting upright & $\begin{array}{l}\text { Arms abducted to } \\
\text { horizontal, palms facing } \\
\text { downwards }\end{array}$ & $\begin{array}{l}\text { Distal third of upper arm, } \\
\text { immediately proximal to } \\
\text { lateral epicondyle }\end{array}$ \\
\hline Wrist extensors & Sitting upright & Wrist fully extended & $\begin{array}{l}\text { Distal portion of second } \\
\text { metacarpus }\end{array}$ \\
\hline Hip flexors & Supine & $\begin{array}{l}\text { Leg straight at } 45^{\circ} \text { above } \\
\text { horizontal }\end{array}$ & $\begin{array}{l}\text { Junction of distal and middle } \\
\text { thirds of thigh }\end{array}$ \\
\hline Knee extensors & Supine & $\begin{array}{l}\text { Hip and knee joints flexed } \\
\text { to } 90^{\circ} \text {; examiner's forearm } \\
\text { behind knee as fulcrum }\end{array}$ & $\begin{array}{l}\text { Anterior aspect of leg at } \\
\text { level of malleoli }\end{array}$ \\
\hline Dorsiflexors of feet & Supine & Foot dorsiflexed to $90^{\circ}$ & $\begin{array}{l}\text { Distal portion of first } \\
\text { metatarsus }\end{array}$ \\
\hline
\end{tabular}


and a standardized technique was followed (Table II). A myometer reading was taken of the force required to overcome the subject's muscle contraction. The procedure was performed three times for each muscle group. Care was taken that the children understood the procedure. The competitive element that readily developed in both surveys was encouraged.

Reproducibility. Myometer examination and measurement of times for elevation of the head and leg was done in 19 children ( 11 boys, 8 girls) between the ages of 4 and 13 years. The examinations were conducted along the same lines as in the school surveys except that both sides of the body were examined. One month later the same measurements were repeated in 18 of the children in order to assess the variations that occur. The opportunity was taken to ascertain the degree of asymmetry that might be present in muscle groups in normal children. Throughout these surveys the myometer was periodically calibrated against a load cell and the degree of variation never exceeded the original instrumental accuracy of $\pm 3 \%$.

Children with muscle disease. A group of children with muscle disease attending the muscle clinics at Hammersmith Hospital were also assessed along the same lines as above.

\section{Results}

\section{Normal children.}

Timed performance tests. The results of our examinations are summarized in Table III. A

TABLE III

Simple muscle performance tests in children

\begin{tabular}{|c|c|c|}
\hline \multicolumn{3}{|c|}{ Minimum time head held off couch (s) } \\
\hline Children age & $\begin{array}{cl}5-6(y r) & (n=47) \\
7-10 & (n=170) \\
11-15 & (n=78)\end{array}$ & $\begin{array}{l}12 \\
30 \\
60\end{array}$ \\
\hline \multicolumn{3}{|c|}{ Minimum time leg raised to $45^{\circ}$ in supine (s) } \\
\hline Children aged & $\begin{array}{cl}5-6(\mathrm{yr}) & (\mathrm{n}=45) \\
7-10 & (\mathrm{n}=169) \\
11-15 & (\mathrm{n}=92)\end{array}$ & $\begin{array}{l}60 \\
40 \\
80\end{array}$ \\
\hline
\end{tabular}

wide variation in performance times was found, with some children being able to hold up their head or leg indefinitely. There appeared to be no difference between boys and girls.

A stepwise multiple linear regression analysis was performed on the results and the variables that were investigated in relation to the head elevations included age, weight, height, head circumference, and strength of neck flexors. In the leg elevation procedure the variables investigated included age, height, weight, and the force of hip flexors as measured on a myometer. The analyses failed to show a correlation of any of the variables with the performance times. For clinical purposes an indication of the minimum times for which the two procedures could be performed has been estimated from scatter diagrams. These minimum times are an approximation to a ' 5 th centile line' and we would therefore expect that approximately $95 \%$ of normal children would have performance times greater than these.

Myometer examination. There was a wide variation in the strength measurements in the second school survey, which was more pronounced in the older children. There again appeared to be no difference in the performance times by boys and girls. The strength in the hip flexors and knee extensors of a number of the older children was equal to or greater than the upper limit of the myometer scale used ( 220 Newtons; $22 \mathrm{kgf}$ ). This meant that the same statistical analysis to determine a minimum normal value could not be applied to all the muscle groups. A minimum value of muscle strength for each muscle group was derived from a ' $n$ ear fit' 5 th centile line on a scatter diagram (Fig. 2). These '5th centile lines' obtained from our second school survey on 215 children are summarized in relation to weight and height respectively (Figs. 3 and 4). Linear regression analysis using a BMDO3R program was performed for the strength of the neck flexors, deltoids, wrist extensors, and dorsiflexors of the foot in relation to height, weight, and age of the subjects. The correlation coefficients derived from the analysis are given in Table IV.

Reproducibility and symmetry. The variation in repeated strength measurements in 18 children did not often exceed $\pm 15 \%$ of the initial values (Fig. 5). The difference in strength on the two sides was less than $15 \%$ of the right-sided values. All the children had strength measurements that were equal to or greater than the minimum values shown in Figs. 3 and 4. In the performance tests 17 of this group of children had times for head elevation and leg elevation that were greater than the minimum values in Table III. However, there were large variations in the times on repeated measurements and also large variations in performance times between right and left sides.

Children with muscle disease. Measurements of times for elevation of the head and the legs were made in 16 children. In this group 32 had Duchenne dystrophy, 8 limb girdle dystrophy, 11 intermediate severity spinal muscular atrophy, 

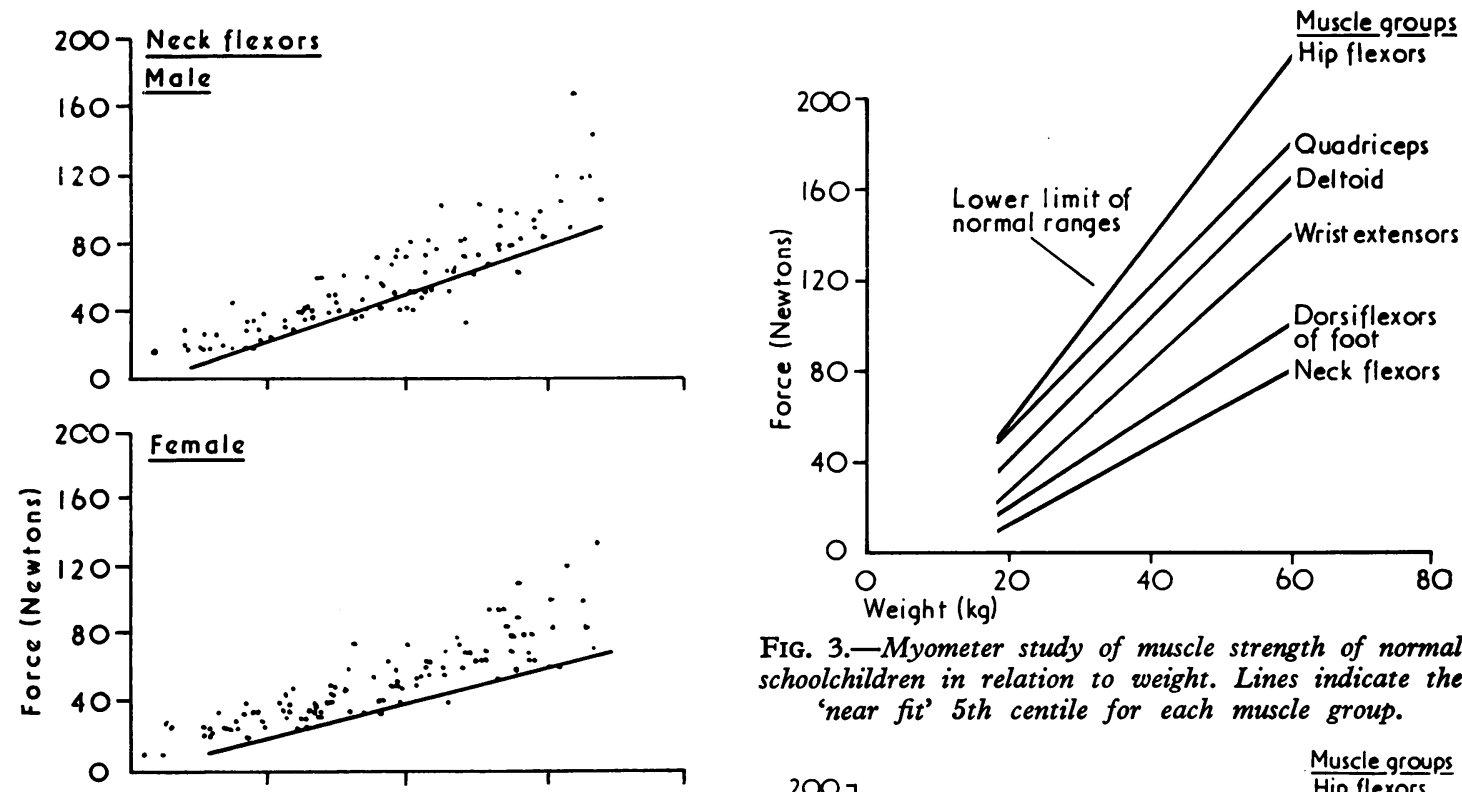

FIG. 3.-Myometer study of muscle strength of normal schoolchildren in relation to weight. Lines indicate the 'near fit' 5th centile for each muscle group.

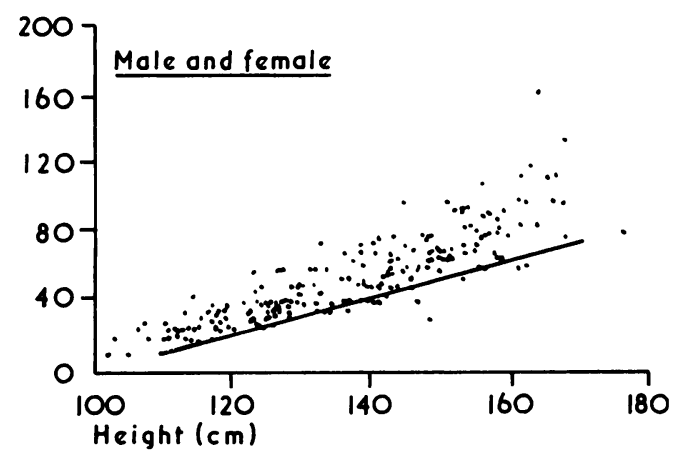

FIG. 2.-Scatter diagram for normal schoolchildren showing 'near fit' 5th centile line. Conversion: SI to traditional units-Newtons: $10 \mathrm{~N} \approx 1 \mathrm{kgf}$.

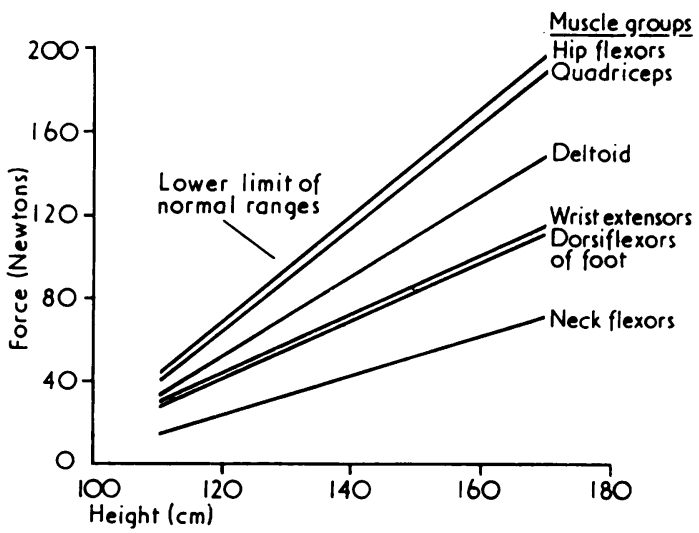

FIG. 4.-Myometer study of muscle strength of normal schoolchildren in relation to height. Lines indicate the 'near fit' 5th centile for each muscle group.

TABLE IV

Correlation coefficients for strength measurements

\begin{tabular}{|c|c|c|c|c|}
\hline & $\begin{array}{l}\text { Neck } \\
\text { flexors }\end{array}$ & Deltoid & $\begin{array}{c}\text { Wrist } \\
\text { extensors }\end{array}$ & $\begin{array}{l}\text { Dorsiflexors } \\
\text { of foot }\end{array}$ \\
\hline $\begin{array}{l}\text { Height } \\
\text { Male } \\
\text { Female } \quad(n=107) \\
\text { Male \& female } \quad(n=215)\end{array}$ & $\begin{array}{l}0.852 \\
0 \cdot 872 \\
0 \cdot 860\end{array}$ & $\begin{array}{l}0.799 \\
0.818 \\
0.797\end{array}$ & $\begin{array}{l}0.720 \\
0.795 \\
0.746\end{array}$ & $\begin{array}{l}0.697 \\
0.706 \\
0.699\end{array}$ \\
\hline $\begin{array}{l}\text { Weight } \\
\text { Male } \\
\text { Female } \quad(n=107) \\
\text { Male \& female } \quad(n=215)\end{array}$ & $\begin{array}{l}0.840 \\
0.870 \\
0.852\end{array}$ & $\begin{array}{l}0.780 \\
0.783 \\
0.768\end{array}$ & $\begin{array}{l}0.685 \\
0.749 \\
0.700\end{array}$ & $\begin{array}{l}0.660 \\
0.684 \\
0.665\end{array}$ \\
\hline $\begin{array}{ll}\text { Age } & \\
\text { Male } & (n=107) \\
\text { Female } & (n=108) \\
\text { Male \& female } & (n=215)\end{array}$ & $\begin{array}{l}0.877 \\
0.865 \\
0.866\end{array}$ & $\begin{array}{l}0.839 \\
0.815 \\
0.808\end{array}$ & $\begin{array}{l}0.719 \\
0 \cdot 763 \\
0 \cdot 722\end{array}$ & $\begin{array}{l}0.670 \\
0.689 \\
0.673\end{array}$ \\
\hline
\end{tabular}




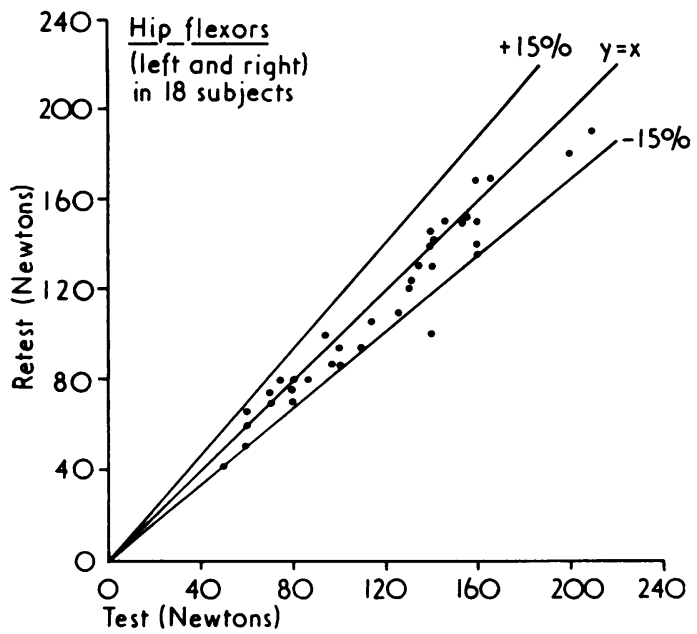

FIG. 5.-Repeatability of myometer measurement of muscle strength in children. Interval of 1 month between test and retest.

and 10 various congenital myopathies. The minimum times for head elevation for their age groups were not achieved by $89 \%$ and the minimum for leg elevation were not achieved by $77 \%$. In all, $92 \%$ failed to produce normal times in one or other of the tests. Of the 5 children $(8 \%)$ with normal results in both tests, 2 had limb girdle dystrophy, one 9 year old a mild intermediate form of spinal muscular atrophy, and 2, aged 6 and 8 years, had Duchenne dystrophy.

Myometer measurements carried out in 32 boys with Duchenne dystrophy are shown in Fig. 6,
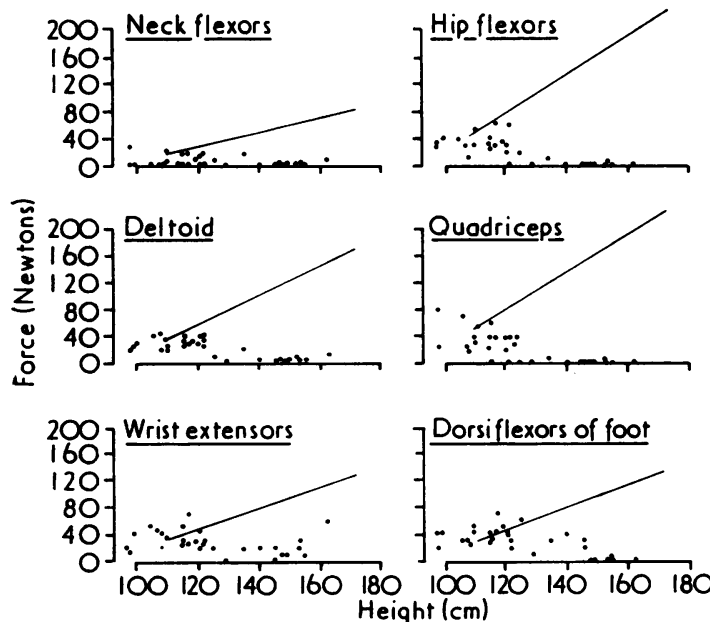

FIG. 6.-Force measurements in boys with Duchenne muscular dystrophy. Lines shown are the lower limits of normal (see Fig. 3). and values obtained in 30 children without muscle disease (and not included in the school surveys) are shown in Fig. 7.

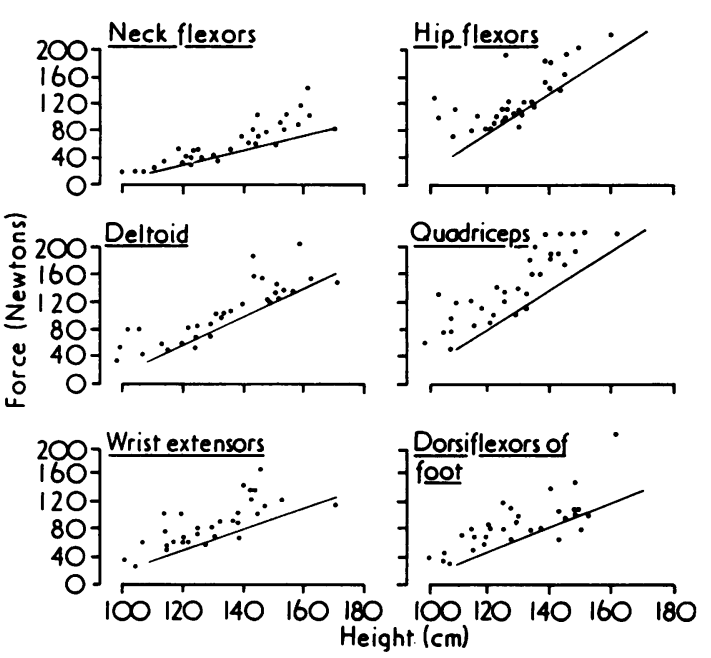

FIG. 7.-Force measurements in normal children. Lines shown are the lower limits of normal (see Fig. 3).

\section{Discussion}

The measurement of power with the myometer gave results that were reproducible and similar to a comparable study performed in children by Asmussen (1969). The strength of the neck flexors, deltoids, wrist extensors, and dorsiflexors of the foot showed good correlation for height, weight, and age in both sexes. There was no apparent difference in strength between boys and girls. Asmussen and Heebøll-Nielsen (1956) have found that the differences in isometric strength between boys and girls were more marked in adolescence, while Jones (1949) found size to account for at least part of the differences in isometric strength between the sexes in the adolescent age group. There was a wide variation in strength and this variation became larger with increasing age (Jones, 1949). Therefore, for clinical purposes a minimum value for isometric strength is used. The limitation of the hand-held device was seen in the measurement of the power of the quadriceps and hip flexor muscle groups when the majority of the older children in the school surveys had strengths greater than the upper range of the myometer. An extension of the measuring range would not have been helpful as the limiting factor would then have been the ability of the examiner to oppose the subjects' contractions (Martin and Rich, 1918; Newman, 1949; Beasley, 
1956; Edwards and McDonnell, 1974). Very large forces are generated by the larger muscle groups. La Hire (1699) suggested that the strength of the 'muscle of the leg' must be at least ' 140 pounds' in order to enable a man to rise from the floor. Measurements made of the larger groups since that time confirm that the forces involved are too large to be measured with a hand-held device (Haxton, 1944/45; Wakim et al., 1950; Beasley, 1956). Therefore the measurement of muscle strength with a myometer must be limited to monitoring of weak muscles in disease or to the smaller muscle groups in normals.

The measurement of force of muscle groups must depend upon the nature of the lever systems around which that group acts and through which the measurement is made (Newman, 1949; Wakim et al., 1950; Elkins, Leden, and Wakim, 1951; Darcus, 1952; Bäcklund and Nordgren, 1968; Asmussen, Hansen, and Lammert, 1965). Therefore, any change in the length of the lever system between successive measurements will militate against reproducibility. In addition to this, it has been shown that there is for every muscle an optimum length at which maximum force will be produced (Hugh-Jones, 1946/47; Clarke et al., 1950; Haffajee, Moritz, and Svantesson, 1972) and this length may be influenced by the angle of adjacent joints. It is therefore important that there is no change in these angles between measurements. Adequate fixation of surrounding joints(Beasley, 1956), minimal distraction (Delorme, 1945), and a competitive attitude (Jones, 1949; Tornvall, 1963) are all helpful in allowing a subject to give a maximal effort. It is important when comparing different series of measurements to learn the principles of the measurements, equipment, procedure, and position used (Tornvall, 1963). Care must be taken in using the myometer that a part of the examiner's hand does not come between the myometer and the part being tested. Stability may be aided by a short curved applicator on which the myometer bellows may rest when examining larger muscle groups.

In children with neuromuscular disease $8 \%$ gave normal results with both performance tests. In the study by Fessel et al. (1970) $7 \cdot 4 \%$ of the adult patients gave normal results on two or more of the tests. The decreased ability to hold the leg up of 7- to 10-year-old children, as compared to younger children, is possibly related to physical development at this age. Motivation and co-operation do not seem to explain this fall in performance as the times for head elevation in the same group did not show a decrease. The variation between the right and left sides and between measurements on different occasions in our normal subjects suggest that these performance tests, though suitable for identifying muscle weakness, are not a sufficiently sensitive means of monitoring the progress of a disease.

We are grateful to the Sir William Coxen Trust for a grant for this study and to the Wellcome Trust and the Muscular Dystrophy Group of Great Britain for support of our neuromuscular research programme. U.S.B. held a Commonwealth Travelling Fellowship. Mr. Michael McDonnell, Royal Postgraduate Medical School, made the prototype myometers used in the surveys.

\section{REFERENCES}

Asmussen, E. (1969). Muscle strength. Scandinavian Fournal of Clinical and Laboratory Investigation, 24, Suppl., 106.

Asmussen, E., and Heebøll-Nielsen, K. J. (1956). Physical performances and growth in children. Influence of sex, age and intelligence. Fournal of Applied Physiology, 8, 371.

Asmussen, E., Hansen, O., and Lammert, O. (1965). Relation between isometric and dynamic muscle strength in man. Communications from the Testing and Observation Institute. No. 20. Danish National Association for Infantile Paralysis.

Băcklund, L., and Nordgren, L. (1968). A new method for testing isometric muscle strength under standardized conditions. Scandinavian Fournal of Clinical and Laboratory Investigation, 21, 33.

Beasley, W. C. (1956). Influence of method on estimates of normal knee extensor force among normal and post polio children. Physical Therapy Review, 36, 21.

Clarke, H. H. (1948). Objective strength tests of affected muscle groups involved in orthopedic disabilities. Research Quarterly, $19,118$.

Clarke, H. H., Elkins, E. C., Martin, G. M., and Wakim, K. G. (1950). Relationship between body position and the application of muscle power to movements of the joints. Archives of Physical Medicine and Rehabilitation, 31, 81 .

Darcus, IH. D. (1952). Strain-gauge dynamometer for measuring the strength of muscle contraction and for re-educating muscles. Annals of Physical Medicine, 1, 163.

Delorme, T. L. (1945). Restoration of muscle power by heavyresistance exercises. Fournal of Bone and foint Surgery, 27, 645.

Edwards, R. H. T., and McDonnell, M. (1974). Hand-held dynamometer for evaluating voluntary muscle-function. Lancet, 2, 757.

Elkins, E. C., Leden, U. M., and Wakim, K. G. (1951). Objective recording of the strength of normal muscles. Archives of Physical Medicine and Rehabilitation, 32, 639.

Fessel, W. J., Taylor, J. A., and Johnson, E. S. (1970). Evaluating the complaint of muscle weakness. Simple quantitative clinical tests. 1st International Congress on Muscle Diseases, p. 544. Ed. by J. N. Walton, N. Canal and G. Scarlato. Excerpta Medica, Amsterdam.

Haffajee, D., Moritz, U., and Svantesson, G. (1972). Isometric knee extension strength as a function of joint angle, muscle length and motor unit activity. Acta Orthopaedica Scandinavica, 43, 138.

Haxton, H. A. (1944/45). Absolute muscle force in ankle flexors of man. Fournal of Physiology, 103, 267.

Hugh-Jones, P. (1946/47). The effect of limb position in seated subjects on their ability to utilize the maximum contractile force of the limb muscles. Fournal of Physiology, 105, 332.

Jones, H. E. (1949). Motor Performance and Growth: $A$ Developmental Study of Static and Dynamometric Strength. University of California Press, Los Angeles.

Kendall, H. O., and Kendall, F. P. (1938). Care during recovery period in paralytic poliomyelitis. U.S. Public Health Bulletin, 242, 30 .

Kendall, H. O., Kendall, F. P., and Wadsorth, G. E. (1971). Muscles: Testing and Function, 2nd ed. Williams and Wilkins, Baltimore. 
Lahey, F. H. (1926). Quadriceps test for the myasthenia of thyroidism. Fournal of the Amercan Medical Association, 87, 754.

La Hire, P. de (1699). Examen de la force de l'homme. Mémoires de l'Académie Royale des Sciences, p. 153. Paris (published 1718).

Lovett, R. W. (1915). The treatment of infantile paralysis. Fournal of the American Medical Association, 64, 2118.

Lovett, R. W. (1916). Treatment of Infantile Paralysis, p. 123. Heinemann, London.

Lovett, R. W., and Martin, E. G. (1916a). Certain aspects of infantile paralysis with a description of a method of muscle testing. Fournal of the American Medical Association, 66, 729.

Lovett, R. W., and Martin, E. B., (1916b). The spring balance muscle test. American fournal of Orthopedic Surgery, 14, 415.

Martin, E. G., and Lovett, R. W. (1915). A method of testing muscular strength in infantile paralysis. Fournal of the American Medical Association, 65, 1512.
Martin, E. G., and Rich, W. H. (1918). Muscular strength and muscular symmetry in human beings. II. Adult males. American fournal of Physiology, 47, 29.

Medical Research Council. (1943). Aids to the Investigation of Peripheral Nerve Injuries. War Memorandum No 7, 2nd ed. H.M.S.O., London.

Newman, L. B. (1949). A new device for measuring muscle strength. The myometer. Archives of Physical Medicine and Rehabilitation, 30, 234.

Tornvall, G. (1963). Assessment of physical capabilities. Acta Physiologica Scandinavica, 58, Suppl. 201.

Wakim, K. G., Gersten, J. W., Elkins, E. C., and Martin, G. M. (1950). Objective recording of muscle strength. Archives of Physical Medicine and Rehabilitation, 31, 90.

Correspondence to Dr. R. H. T. Edwards, Jerry Lewis Muscle Research Centre, Royal Postgraduate Medical School, Hammersmith Hospital, London W. 12.

The following articles will appear in future issues of this journal:

Fibrosing alveolitis in infancy and childhood. C. J. Hewitt, D. Hull, and Jean W. Keeling.

Influence of folic acid on birthweight and growth of the erythroblastotic infant. I, II, and III.

Gillian Gandy and W. Jacobson.

Peritoneal dialysis in children. A review of eight years' experience. Ruth E. Day and R. H. R. White.

Milk bolus obstruction in the neonate. C. T. Lewis, J. A. S. Dickson, and V. A. J. Swain.

Evaluation of a new mineral and trace metal supplement for use with synthetic diets. Margaret $S$. Larvson,

Barbara E. Clayton, H. T. Delves, and J. D. Mitchell.

The natural history of Hartnup disease. Bridget Wilcken, J. S. Yu, and D. A. Brown.

Myelomonocytic leukaemia with a preleukaemic syndrome and $\mathrm{Ph}^{1}$ chromosome in monozygotic twins.

Eva Svarch and E. de la Torre.

Use of a simple duodenal capsule to study the upper intestinal microflora. M. Gracey, Suharjono, and Sunoto. 